\title{
An integrated approach to the creation of decentralized power supply systems based on gas turbine plants in the regions of the Far North
}

\author{
Pavel Kolpakhchyan ${ }^{1, *}$, Boris Lobov², Ivan Ivanov ${ }^{3}$, and Alfred Safin ${ }^{4}$ \\ ${ }^{1}$ Rostov State Transport University, Rostov-on-Don, Russian Federation \\ ${ }^{2}$ Platov South-Russian State Polytechnic University (NPI), Novocherkassk, Russian Federation \\ ${ }^{3}$ Russian Energy Agency, Russian Federation \\ ${ }^{4}$ Kazan State Power Engineering University, Kazan, Russian Federation
}

\begin{abstract}
This article considers power supply of consumers in the Far North. It is proposed to use systems which include units operating on liquefied natural gas and hydrogen. Such units have a number of advantages over the currently used diesel power plants. The main advantage is a significant reduction of emissions to air and environmental pollution. The use of gas turbine units, comprising a turbine and a highspeed generator, also allows one to reduce the weight and dimensions of the power plant. The issues of choosing the structure of the power supply system for the given operating conditions are considered: the basic requirements are formulated and a list of quality indicators of the system functioning is determined.
\end{abstract}

\section{Introduction}

Electricity supply to consumers in the zones of decentralized power supply is currently carried out from autonomous diesel power plants (DPP). The priority direction of the socio-economic development of such zones is to improve the reliability and efficiency of the region's decentralized power supply complex.

The main tasks to improve energy efficiency are the following:

- Reducing the volume and cost of fuel used.

- Reducing the specific fuel consumption per $1 \mathrm{kWh}$ generation.

- Improving the reliability and safety of power supply.

An integrated approach to the DPP modernization program can increase the energy efficiency of the decentralized power supply complex in a region while ensuring significant savings in financial costs.

One of the options for this approach can be a program for converting DPP to use liquefied natural gas (LNG) and hydrogen with optimization of the composition and operating modes of the main electrical equipment $[1,2]$.

The basis for the implementation of this program is:

- Low cost of natural gas.

- Difficult climatic conditions in the northern territories of the country that favorably affect the technology of LNG production.

- Available technologies for hydrogen production, for example, from industrial aluminum powders.

- Large consumption of diesel fuel in the region (more than 270 thousand tons of fuel equivalent).
- Complex and expensive logistics for the delivery of fuel for diesel power plants [3].

\section{The degree of scientific development of the issue}

The choice of fuel type: LNG and/or hydrogen is determined by the presence or absence in a particular region of a local (within a radius of up to $300 \mathrm{~km}$ from the place of consumption) LNG production. With the presence of such a production, the time and cost of LNG delivery are significantly reduced [4-6]. However, due to its physical and chemical properties, LNG must be stored in cryogenic isothermal tanks, which imposes additional requirements on fuel storage systems and limits its use $[7,8]$. The use of hydrogen instead of LNG is justified in regions where there is no LNG production and its delivery is not profitable. For the production of hydrogen, a special installation is also required - a hydrothermal reactor; the thermal effect of the reaction occurring in it can be used to create cogeneration plants. These problems designate the need for the combined use of LNG and hydrogen fuel, which allows reducing the cost of LNG storage systems. The enterprises of Rostec Group of Companies have developed LNG storage systems that can ensure drainless storage of the product for up to 3 months. The developed design documentation for such a system describes the storage period of up to 163 days [9]. In the future all this will allow to significantly expand the list of objects for LNG gasification.

\footnotetext{
*Corresponding author: kolpahchyan@mail.ru
} 
It should be noted that, for example, in the Arkhangelsk region, $40 \%$ of generating facilities (electricity, heat) are located in the zone of year-round transport accessibility, and $35 \%$ of generating facilities are in the zone of a 3-month break, which already allows efficient use of the existing LNG storage systems.

The use of alternative energy sources as well as LNG instead of oil and coal can significantly reduce, and when using hydrogen, eliminate emissions into the atmosphere and prevent environmental pollution caused by spills and transfer of oil fuels [10-12].

Spills of oil products and oil are very dangerous for nature. Spills have an immediate and prolonged effect. Climatic conditions, the need to mobilize equipment and people with displacements over long distances, significantly complicate elimination of oil and oil products spills on water, ice, or ground. Cleaning oil spills on ice is particularly difficult, and there are very few methods for responding to such spills.

LNG, due to its physical properties, when spilled on soil, ice and water, does not pollute the environment like oil. During the use and operation of LNG, there have been no significant accidents in the world with a large amount of LNG spilled onto the ground or water. According to DNV32, the maximum spill volume was $40 \mathrm{~m} 3$ for the entire period of LNG sea transportation. The LNG storage temperature is significantly lower than ambient temperatures, even in winter in the Arctic; therefore, in the event of a spill, LNG evaporates and dissolves in the atmosphere for a short time. The use of LNG will significantly reduce the scale of environmental pollution [13-18].

The use of gas as a fuel in any case leads to a decrease in emissions into the atmosphere. The largest decrease is recorded for SOx, particulate matter, NOx emissions are reduced by $80 \%$. Greenhouse gas (GHG) emissions are less when using LNG.

During the production and combustion of hydrogen, water vapor is released into the atmosphere, that is, there is no environmental pollution.

\section{Requirements for the power supply system}

The most important technical characteristics of the decentralized power supply system (DPSS), which provides power to decentralized consumers, are the number and capacity of installed power units; the LNG reception, storage, and regasification facility (RSRF); as well as the performance of the hydrothermal reactor. These indicators determine the reliability of power supply to consumers and the efficiency of DPSS operation.

The total capacity of working generating units must cover the maximum design load, taking into account the DPSS own needs and ensure start of electric motors. The number of working units is determined in accordance with the load schedule and the available nomenclature of generating units. The composition of RSRF and the volume of LNG storage are determined not only by fuel consumption of power units and the regulatory minimum supply level of fuel (RMSLF), but also by the conditions of LNG delivery to the facility. For northern regions with year-round transport accessibility, it takes at least 5 days.

Basic requirements for DPSS equipment include:

1. The structure of DPSS consumers differs significantly in terms of power, quantity and operating modes; also, the load of complex will inevitably change in a significant range, both during the day and according to the seasons. It is desirable to ensure the loading of power plants in the range from 40 to $80 \%$ of the nominal load $[10,11]$. Loading above these limits leads to a decrease in the resource of the gas engine; at low loads, the specific fuel consumption increases significantly.

2. Power plants based on LNG and hydrogen must be periodically taken out of service to carry out the necessary maintenance, current and major repairs. At the same time, the reliability of power supply to consumers is ensured by reserve installations and storage batteries.

3 . The RSRF storage system must ensure the required periods of non-drainage storage of the product.

DPSS is formed from 3 groups of power units:

1st group: Main.

The power plant(s) operates in the basic mode at the existing stable load with a load from $50 \%$ to $80 \%$.

2nd group: Reserve.

The power plant creates a power reserve for automatic loading and shedding.

3rd group: Emergency.

Each of the listed DPSS groups may include:

- Gas piston and/or gas turbine generator unit from $125 \mathrm{~kW}$ to $1 \mathrm{MW}$ of installed capacity;

- Autonomous or mobile RSRF with storage capacity from $20 \mathrm{~m} 3$ to $2000 \mathrm{~m} 3$ of LNG;

- Power plant using hydrogen with an installed capacity of 0.125 and $0.25 \mathrm{MW}$;

- Rechargeable battery for work with a load of $40 \mathrm{~kW}$ for 12 hours.

\section{Choosing the structure and composition of the system}

Modular structure with fittings provides a wide choice of both composition and capacities of a specific DPSS. A possible structure of a decentralized power supply system is shown in Fig. 1.

The following notations are used in Fig.1: GGU1 GGU4 are the main and standby gas-generator units (LNG, hydrogen); ATS is the automatic transfer switch; CSB is the control system board; LDB is the load distribution board; SB is the storage battery.

When choosing the structure and composition of DPSS, in addition to the number and capacity of installed power units listed above, as well as the volume of RSRF, it is necessary to take into account efficiency, power quality, flexibility, reliability of power supply, operational safety and the cost of $1 \mathrm{kWh}$ of electricity.

Thus, the problem of choosing a DPSS structure is reduced to a discrete multicriteria problem (MCP) of choosing the appropriate technical solution. 


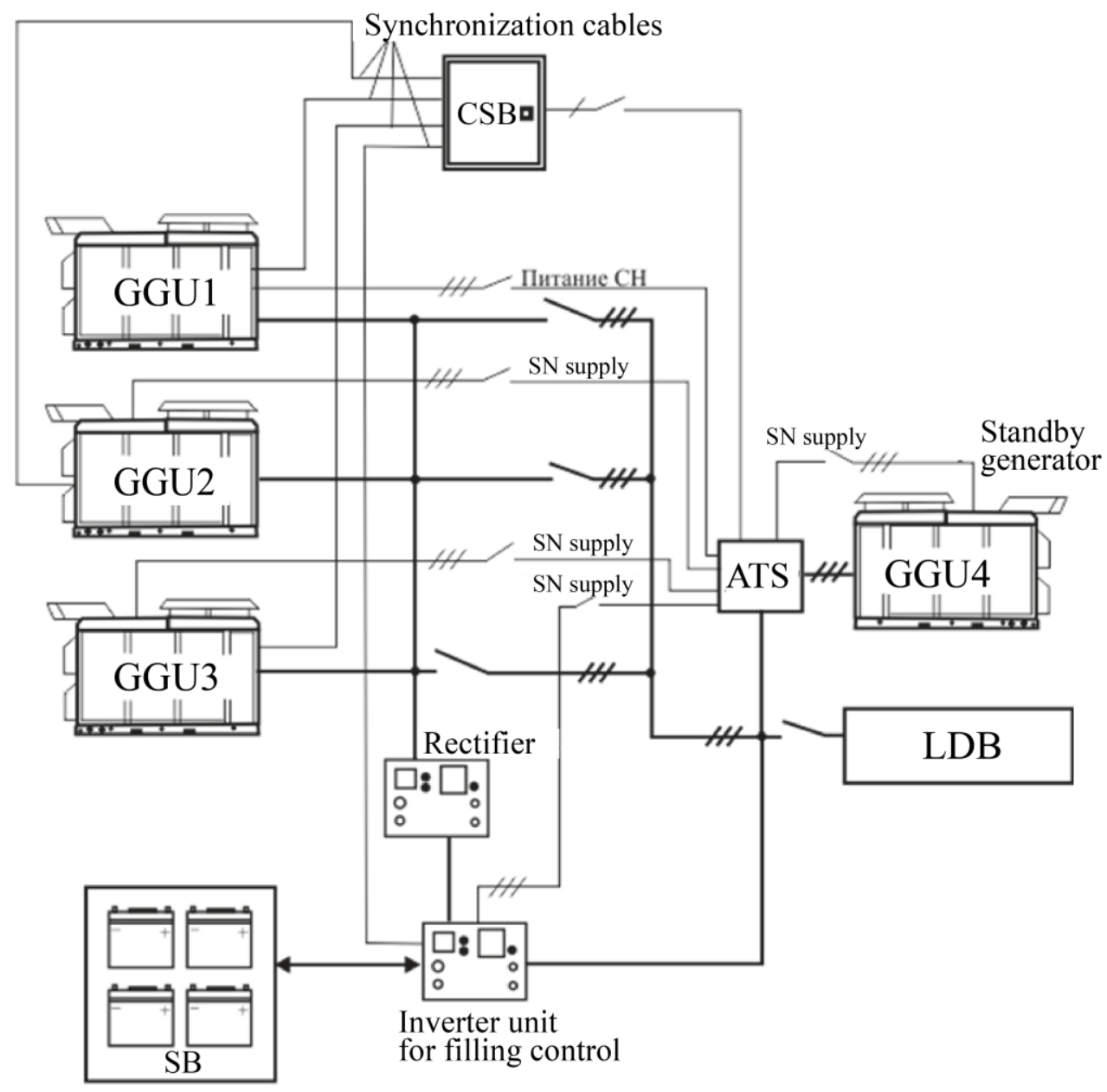

Fig. 1. Block diagram of a decentralized power supply system.

The mobile energy complex MEC-LNG-125/800 with a capacity of $125 \mathrm{~kW}$ and a cost of 18 million rubles can be used as a GGU. [12]. The appearance of the complex is shown in Fig. 2.

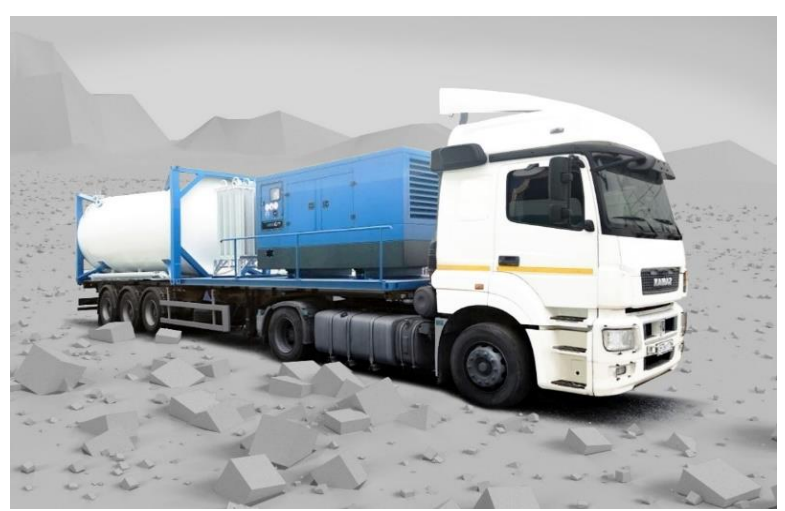

Fig. 2. Mobile LNG-power complex.

The main part of the complex is a gas piston engine that rotates a low-speed generator (GPE LG). The development and use of a gas turbine engine and a highspeed generator (GTE HG), for example, synchronous with permanent magnets, will significantly increase the efficiency of the gas turbine unit and reduce its dimensions. The cost of GGU with GTE HG, excluding the development cost, can be assumed to be equal to the cost of GGU and GPE LG of the corresponding capacity. The cost of a unit fueled by hydrogen, according to rough estimates, is 1.5 times higher than the cost of a gas turbine unit with GTE HG (excluding development costs). Currently, a large number of storage batteries are brought to market, for example, a battery of 240 Sun Stone Power LiFeP04 12-200 batteries (for operation with a load of $40 \mathrm{~kW}$ for 12 hours) with a total cost of $5,000,000$ rubles.

When choosing the composition of a decentralized power supply system, the following eight indicators serve as the selection criteria:

a) Designation indicators: design load (from 0.125 to $2 \mathrm{MW}$ ); consumer operating mode (uniform, nonuniform); gas delivery conditions (less than $300 \mathrm{~km}$, more than $300 \mathrm{~km}$ );

b) Criteria of optimality: cost of $1 \mathrm{kWh}$ of electricity; operational safety; reliability of power supply; system efficiency; flexibility.

It is obvious that the selected optimality criteria are contradictory. So, with all other things being equal, an increase in the number of GGUs (with a decrease in capacity of each of them) results in an increase in the reliability of power supply and the system flexibility, but 
this decreases the efficiency and safety of operation, and increases the cost of $1 \mathrm{kWh}$.

When choosing the number of GGUs of various capacities for a given design load, it pays to limit the total number of units to ten, for example. In this case, the total number of options for the composition of system for the entire range of the design load is equal to 296. Having a matrix of $8 \times 296$ expert assessments of options and using one of the methods for selecting technical solutions, for example, the method of sequential narrowing of the initial set of vector assessments, it is possible to obtain an optimal (according to several criteria) option for composition of decentralized power supply systems.

\section{Conclusions}

1. The use of diesel power plants in the Far North regions leads to envi-ronmental pollution and creates certain difficulties with the delivery of fuel to the places of its consumption.

2. The use of liquefied natural gas and hydrogen as an alternative fuel will reduce emissions into the environment and solve the problem of diesel fuel delivery.

3. Development of modern gas turbine complexes operating on liquefied gas or hydrogen significantly reduces the size and weight of power plants and increases their efficiency.

4. When choosing the structure and composition of decentralized power supply systems, it is necessary to use methods for selecting technical solutions taking into account all the main indicators, which characterize the quality of functioning the power supply system.

\section{Acknowledgements}

The research was carried out within the agreement ("Scientific and tech-nical solutions to develop the efficient high speed generator equipment for micro gasturbine unit” № 14.604.21.0174, 26 September 2017) by order the Ministry of Education and Science of the Russian Federation, Federal Target Program "Development of the focal areas for the development the scientific and technical complex of Russia for 20142020 ". The unique ID for applied research (project) is RFMEFI60417X0174.

\section{References}

1. V.L. Bondarenko, T.V. D’yachenko, Utilization of LNG Exergy. Main Directions Chem. Pet. Eng. (2020)

2. E.V. Vorontsova, A.L. Vorontsov, General assessment of the environmental status and environmental risks in the Arctic zone of the Russian Federation, E3S Web Conf, 161 (2020)

3. E.A. Tyurina, A.S. Mednikov, P.Y. Elsukov S.N. Sushko, Analysis of the efficiency of energy systems of long-distance energy transport, E3S Web Conf. 124 (2019)

4. Anon 2018 Arctic winds will provide energy to the Far North of Russia https://zen.yandex.ru/media/arctic/arkticheskievetra-obespechat-energiei-krainii-sever-rossii5ae81c6adb0cd9e28f7a2f63 2

5. Anon Departmental standards for technological design of installations for production and storage of liquefied natural gas, isothermal storages and gas filling stations (VNTP 51.1-87), approved by the Ministry of Gas Industry 09/13/87.

6. E.V. Shevchuk, Liquefied natural gas storage and industrial safety problems, Int. Res. journal. Eng., 11, 141-143 (2016)

7. Y. Choi, J. Ahn, C. Jo, D. Chan, Prismatic pressure vessel with stiffened-plate structures for fuel storage in LNG-fueled ship, Ocean Eng (2020)

8. F. Lisowski, E. Lisowski, Thermal and mechanical analysis of the internal support for LNG cryogenic road tanker, E3S Web Conf., 128 (2019)

9. Anon PJSC Cryogenmash. LNG Facilities http://www.cryogenmash.com/en/catalog/lngfacilities/

10. N. Ponomareva, A. Zvereva, E. Golubtsova, S. Ilyashenko, G. Ivanov, Certain economic instruments as a factor of realizing the potential of using alternative energy sources in Russia, E3S Web Conf., 124 (2019)

11. Anon 1986 The Russian State Standard GOST 17.2.3.01-86. Protection of Nature. Atmosphere. Air quality control rules for settlements, approved by Resolution No. 3 of the State USSR Committee for Standards

12. N. Politaeva, Y. Smyatskaya, R. Al Afif, C. Pfeifer, L. Mukhametova, Development of Full-Cycle Utilization of Chlorella sorokiniana Microalgae Biomass for Environmental and Food Purposes, Energies, 13 (2020)

13. C. Song, Y. Liu, L. Sun, Q. Zhang, H. Mao, Emissions of volatile organic compounds (VOCs) from gasoline- and liquified natural gas (LNG)fueled vehicles in tunnel studies, Atmos. Environ. 234 (2020)

14. Anon 1987 The Russian State Standard GOST 5542-87. Combustible natural gases for industrial and domestic use. Specifications, approved. Decree No. 36 of the USSR State Standard of 04.16.87

15. Anon 2000 Safety Rules PB 08-342-00. Safety rules for the production, storage and delivery of LNG at gas distribution stations of main gas pipelines and automobile gas filling stations, approved by Resolution No. 3 of Gosgortekhnadzor dated 08.02.2000

16. Anon Specifications TU 51-03-03-85. Combustible natural liquefied gas. Fuel for internal combustion engines, approved by Mingazprom 
17. X. Yuan, B. Zhang, R. Liang, R. Wang, Y. Sun, Environmental impact of the natural gas liquefaction process: An example from China, Appl. Sci., 10 (2020)

18. A. Kalbarczyk-Jedynak W. Mariner Ślączka, Dimensioning of hazardous zones resulting from the release of lng as a function of the type of place of occurred unsealing and unsealing scenario Int. Multidiscip. Sci. GeoConference Surv. Geol. Min. Ecol. Manag. SGEM 19 779-86 (2019)

19. D.A. Cauich-López, L.F. Barrera Payan, A.M.N. Abdelhalim, A.A. Sinitsyn, I.G. Akhmetova, Smallscale steam generation from local solid wastxe, International Journal of Civil Engineering and Technology 10(2), 2118-2129 (2019)

20. A.A. Sinitsyn, N.N. Boytsova, I.G. Akhmetova, E.O. Antonova, B.G. Aksenov, Study of operation of power-generating devices of gaseous fuels combustion, International Journal of Mechanical Engineering and Technology 10(2), 1480-1490 (2019) 